\title{
Oscillatory behaviour during the oxidation of methane over palladium metal catalysts
}

\author{
Xunli Zhang*, Colleen S.-M. Lee, D. Michael P. Mingos ${ }^{1}$, David O. Hayward \\ Department of Chemistry, Imperial College of Science, Technology and Medicine, South Kensington, London, SW7 2AY, UK
}

Received 4 July 2002; received in revised form 30 July 2002; accepted 30 July 2002

\begin{abstract}
Oscillatory reactions over palladium foil and wire catalysts during the oxidation of methane have been investigated over a wide range of reaction temperatures and argon/methane/oxygen feed gas compositions. Characterisation of the catalyst has also been carried out using scanning electron microscopy (SEM) techniques, which revealed the presence of a porous surface. This suggested that the metal surface has undergone a change since the reaction commenced, and using X-ray powder diffraction (XRD) techniques the palladium phase was shown to be the dominant phase present. Hysteresis phenomena were observed in the activity of the reaction as the temperature was cycled up and down, showing that the metal surface was continually changing throughout the reaction. The activation energies of the reaction during the high reactivity mode, PdO, and low reactivity mode, $\mathrm{Pd}$, were also calculated. Oscillation rates were observed to depend on the dominant surface. Oscillations were frequent when the high reactivity mode was dominant while the activation energy of this mode was found to be low. When the low reactivity mode was dominant, the oscillations were slower and the activation energy was three times larger. The results obtained imply that the behaviour of the palladium surface, switching back and forth from the reduced state to the oxidised state, is responsible for the oscillatory behaviour seen in this system.
\end{abstract}

(C) 2002 Elsevier Science B.V. All rights reserved.

Keywords: Oscillations; Methane oxidation; Palladium foil catalyst; Palladium wire catalyst

\section{Introduction}

The partial oxidation of methane to produce $\mathrm{CO}$ and $\mathrm{H}_{2}$ has received increasingly attention in recent years, mainly because of its potential use as a commercial source of syngas $\left(\mathrm{CO}+\mathrm{H}_{2}\right)$. The complexity of the reaction pathways involved in the oxidation of methane can result in oscillatory kinetics under certain circum-

\footnotetext{
* Corresponding author. Present Address: Department of Chemistry, The University of Hull, Hull, HU6 7RX, UK.

Tel.: +44-1482-466369; fax: +44-1482-466416.

E-mail address: x.zhang@hull.ac.uk (X. Zhang).

${ }^{1}$ Present address: St. Edmund Hall, The University of Oxford, Oxford, OX1 4AR, UK.
}

stances. Such oscillations have been observed over palladium catalysts [1-4], and supported nickel catalysts [5-7]. It has been observed in our earlier study that chromel/alumel thermocouple wires and nickels wires can also catalyse the methane/oxygen reaction and result in rate oscillations [8].

Konig and co-workers [1,9] is the first group to observe oscillatory reactions during methane oxidation over a palladium film catalyst. Using ellipsometry to study the growth of the PdO layer on a thick Pd film, it has been found that under certain conditions the film composition can spontaneously oscillate between metal-rich and oxide-rich states, and these oscillations in the palladium film properties were accompanied by 
similar oscillations in the catalyst activity. In a separate study conducted by Ozkan et al. [10], further evidence for the periodic phase changes, observed on the palladium catalyst surface that resulted in reaction rate oscillations, was obtained using thermo-gravimetric analysis and high-temperature XRD techniques. Oscillatory behaviour during methane oxidation was also observed over an alumina supported palladium catalyst in studies carried out by Deng and Nevell [2,4]. It has been found that the amplitude and frequency of the oscillations depended on the feed gas composition and the reaction temperature. A similar oscillatory mechanism to that of Konig has been proposed.

Although it is generally accepted that the oscillatory behaviour over palladium catalysts is due to palladium switching between oxide and reduced states, there is still some disagreement in the literature over the reaction mechanism and, especially, the surface form that is most active. The aim of the work reported here has been to investigate the oscillatory behaviour of methane/oxygen reaction over palladium wire and foil catalysts that have not been studied previously, and to get further evidence for understanding the oscillatory mechanism. This work was, in fact, initiated after oscillations were observed in the reactant and product composition together with reaction temperature when a mixture of methane and oxygen was passed through a quartz tube containing only quartz wool and a chromel/alumel thermocouple. It was evident that the thermocouple wires were catalysing the reaction and this led to the investigation into the catalytic activity of a range of transition metal wires and foils. After analysis of the experimental results a mechanism, which explained the oscillations, has been proposed.

\section{Experimental}

Methane (purity 99.0\%) and oxygen (purity 99.6\%) were purchased from Aldrich. Argon (purified) was supplied by BOC Gas. Both palladium wire ( $0.25 \mathrm{~mm}$ diameter, $99.95 \%$ purity) and palladium foil ( $0.025 \mathrm{~mm}$ thickness, $99.95 \%$ purity) were provided by Goodfellow Ltd.

The catalyst was either a $10 \mathrm{~cm}$ coil of palladium wire, of diameter $0.25 \mathrm{~mm}$, or a piece of $4 \mathrm{~mm} \times 10 \mathrm{~mm}$ palladium foil that was $0.025 \mathrm{~mm}$ thick. Chromel and alumel wires, of $0.5 \mathrm{~mm}$ diameter, were spot-welded separately on to the palladium wire or foil to make a modified chromel-palladium-alumel thermocouple junction, based on the law of intermediate metals [11]. The thermocouple wires were insulated with ceramic sheaths. The structure and the composition of the catalyst surface were determined by the techniques of scanning electron microscopy (SEM) and XRD using a JSM-T200 scanning electron microscope and a PW1710 X-ray diffractometer (Phillips Electronic Instruments) with $\mathrm{Cu} \mathrm{K}$ radiation of wavelength $1.540 \AA$, respectively.

All the reactions were carried out in a laboratoryscale, continuous-flow reaction system with a tubular quartz reactor (i.d. $10 \mathrm{~mm}$ ), which was placed in a conventional tubular furnace over a temperature range of $300-650{ }^{\circ} \mathrm{C}$. All the catalytic reactions were carried out at an overall gas flow rate of $60 \mathrm{~cm}^{3} \mathrm{~min}^{-1}$ unless stated otherwise while the flow rate of the inert gas carrier, argon, was always kept constant at $30 \mathrm{~cm}^{3} \mathrm{~min}^{-1}$. By varying the flow rate of the reactant gases, using mass flow controllers (ASM model AFC-260), methane and oxygen, the different feed gas ratios of methane/oxygen were obtained in a range of 1:1-29:1. A quadrupole mass spectrometer (QMS-SX200D), which allowed time-resolved monitoring of up to 16 different mass numbers simultaneously (plus a temperature channel), was employed to analyse the oscillatory behaviour exhibited by the reaction system. The mass spectrometry data, together with the thermocouple measurements, were recorded by a real-time, computerised data acquisition system (Sensorlab V.5, Fisons Instruments, Vacuum Generators Quadrupoles). Temperature oscillations observed during the reaction were also recorded on an analogue chart recorder. A heating tape was used to heat the tubulation between the reactor outlet and the mass spectrometer to prevent condensation of water produced by the reaction.

\section{Results and discussions}

\subsection{Characterization of the catalyst}

\subsubsection{X-ray diffraction analysis}

It was observed, from the X-ray diffraction patterns of the palladium foil obtained after the reaction, that the palladium peaks $(2 \theta=40.2,46.6,68.0,82.0$ and 
$86.6^{\circ}$ ) featured as the most prominent peaks while some $\mathrm{PdO}$ peaks $\left(2 \theta=33.9\right.$ and $\left.54.9^{\circ}\right)$ were also detected even though they were relatively weak. This indicated that any palladium oxide present was in the form of very small crystallites, probably with dimensions less than $0.1 \mu \mathrm{m}$ and spread as a thin layer across the palladium surface. On the other hand, the palladium sample was cooled, after reaction, to room temperature in the methane/oxygen mixture and as a result, some oxide would inevitably be present.

\subsubsection{Scanning electron microscopy analysis}

Photographs of the palladium surface after undergoing reaction were obtained with the scanning electron microscope. Analysis of the SEM photographs revealed a rough and highly porous surface indicting that the reaction had caused widespread reconstruction of the metal surface. Visually, the surface had a dull grey-brown colour.

In the study of the palladium catalyst during the oxidation of methane conducted by Konig et al. [1], it had been found two different PdO layers were present. The surface either took on a lustrous green or dull brown appearance. Spectroscopic ellipsometry scans confirmed the green appearance to be a dense $\mathrm{PdO}$ layer with low activity for methane oxidation, while the dull brown surface is of a highly porous $\mathrm{PdO}$ layer with higher catalytic activity. It has been seen that the photographs of the oxide layer obtained in this work here were similar to those of the porous oxide obtained by Konig et al. Ruckenstein and co-workers $[12,13]$ have also observed, by using transmission electron microscopy, the formation of porous structure and cavities on Pd crystallites while Pd supported on thin alumina films was oxidised to PdO. The surface restructuring has been attributed to the difference in the interfacial tension where the PdO formed has a lower interfacial tension than the unoxidised metal.

\subsection{Oscillations of methane oxidation over Pd foil and wire}

Figs. 1-4 show the typical oscillatory behaviour exhibited during the oxidation of methane over both the palladium foil and wire at low and high temperatures. It should be pointed out that the QMS signal of the reactants and products illustrated in the figures have been vertically offset by the factors shown in

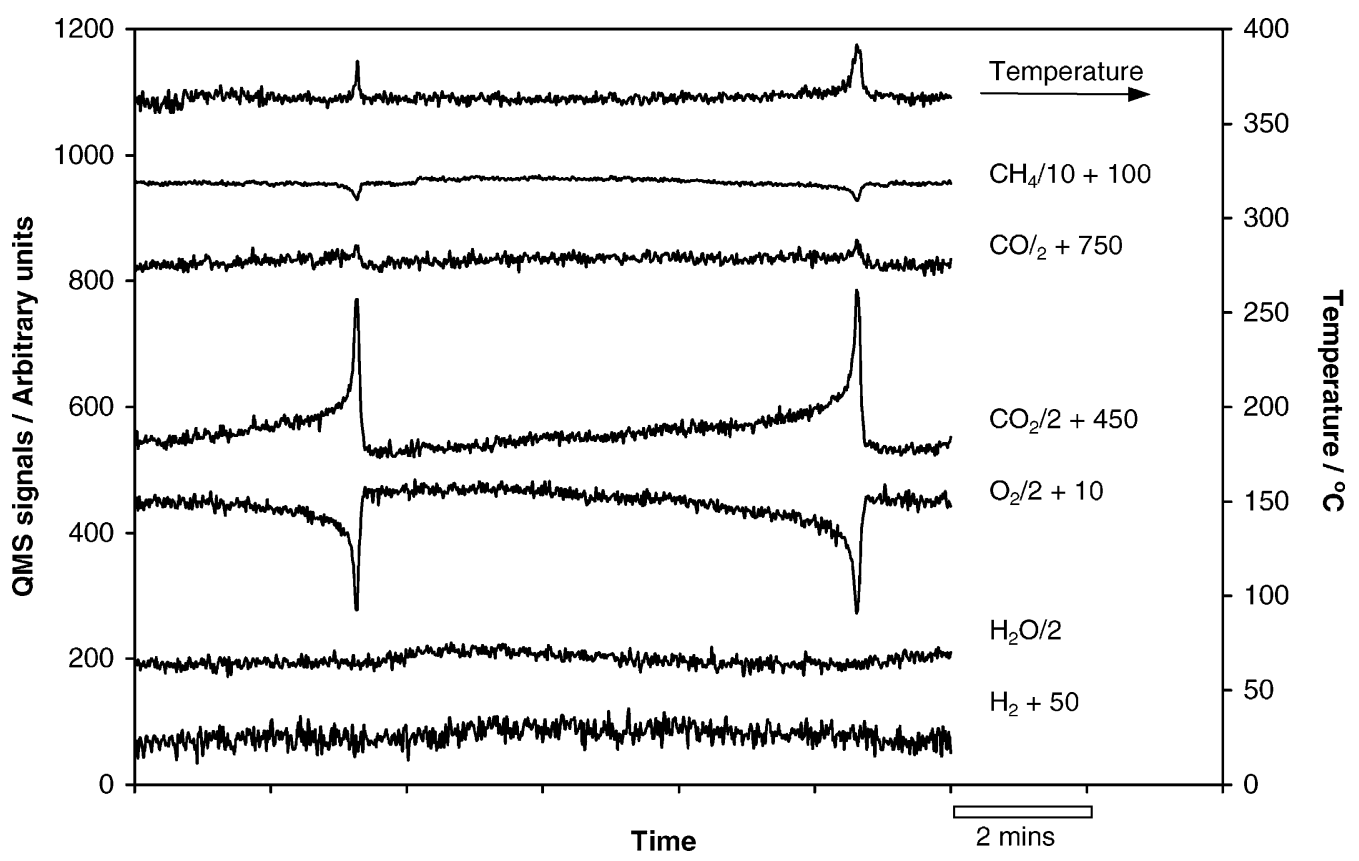

Fig. 1. Oscillations of methane oxidation over palladium foil in the temperature range of $345-390{ }^{\circ} \mathrm{C}$, with methane/oxygen ratio $5: 1$. 


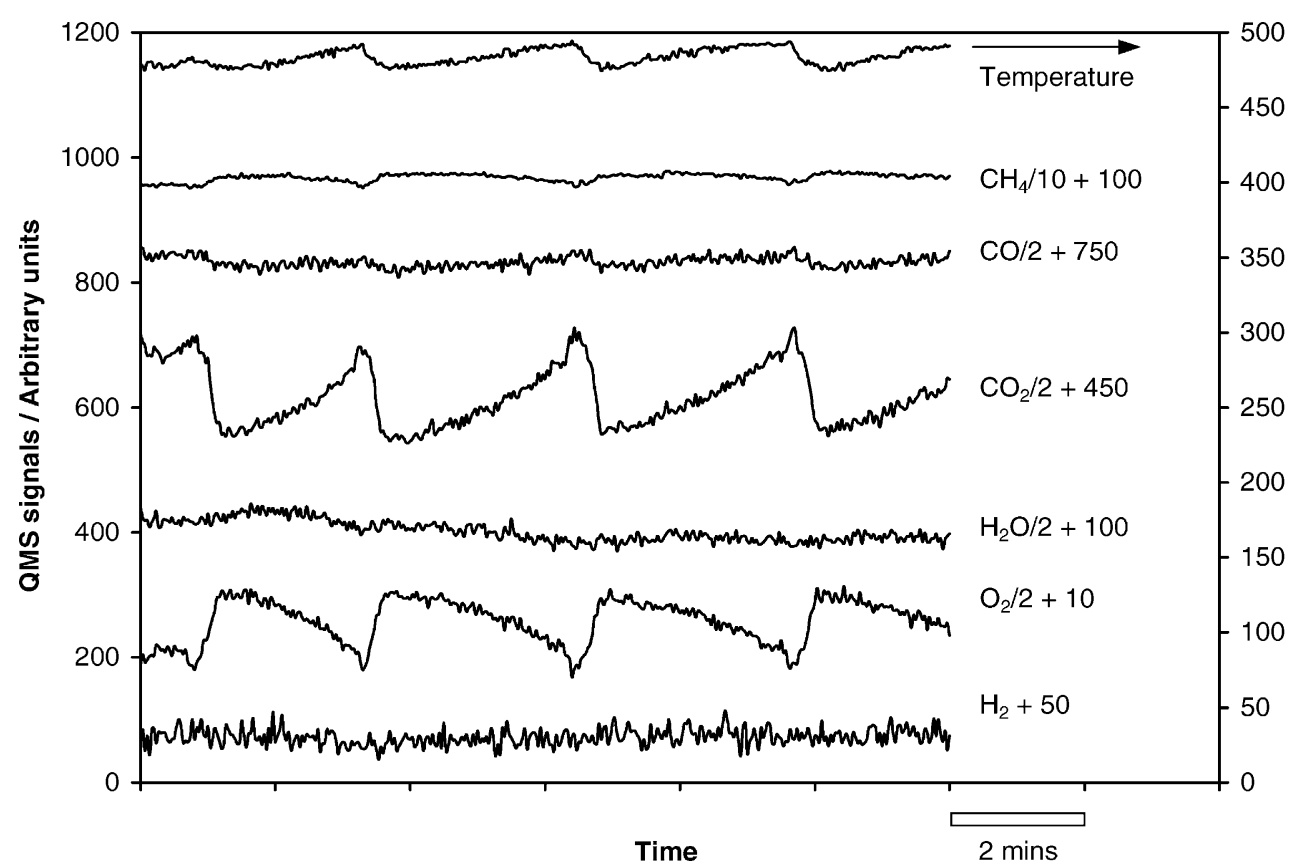

Fig. 2. Oscillations of methane oxidation over palladium foil in the temperature range of $476-492{ }^{\circ} \mathrm{C}$, with methane/oxygen ratio $5: 1$.

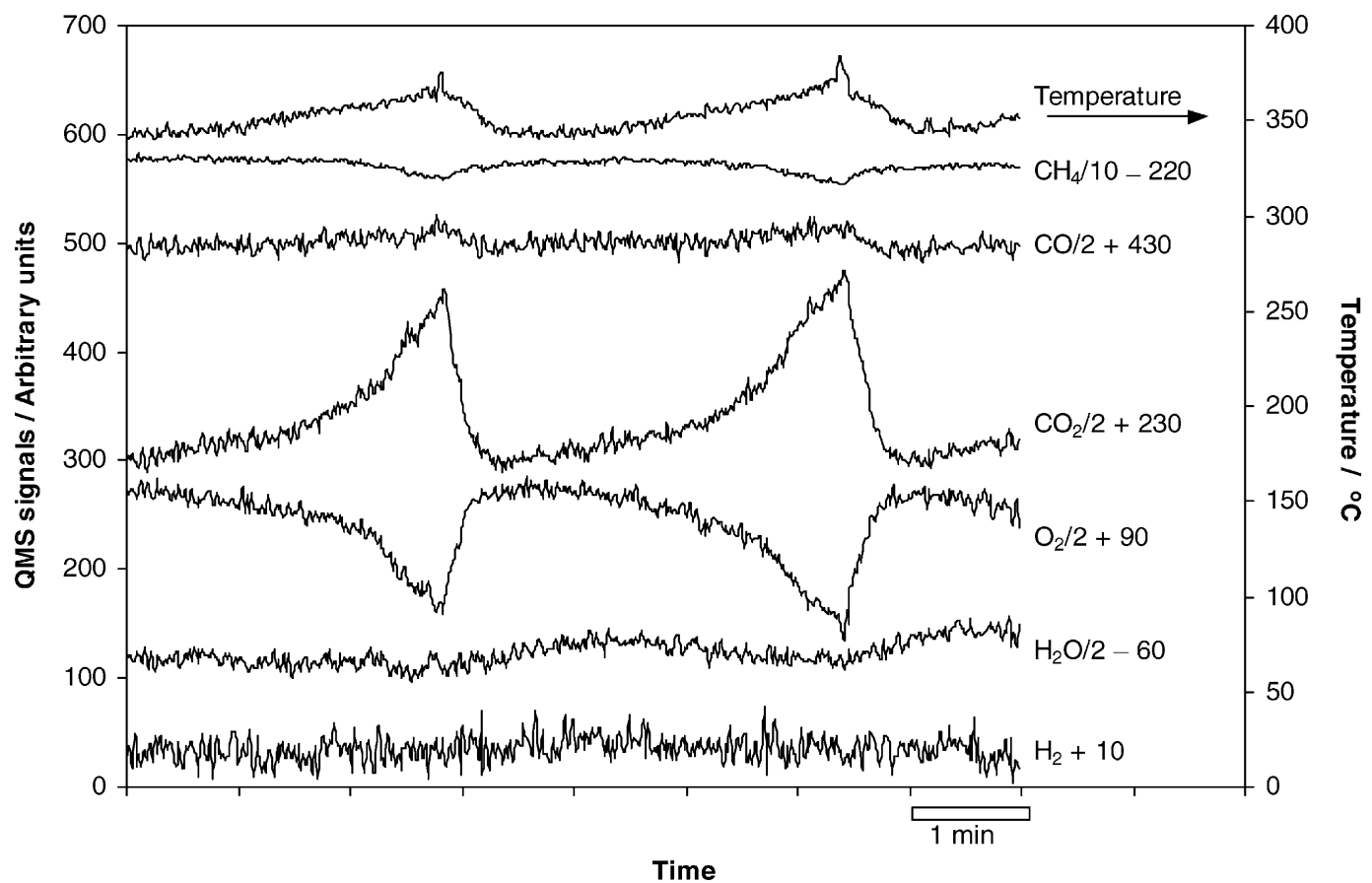

Fig. 3. Oscillations of methane oxidation over palladium wire in the temperature range of $345-384^{\circ} \mathrm{C}$, with methane/oxygen ratio $9: 1$. 


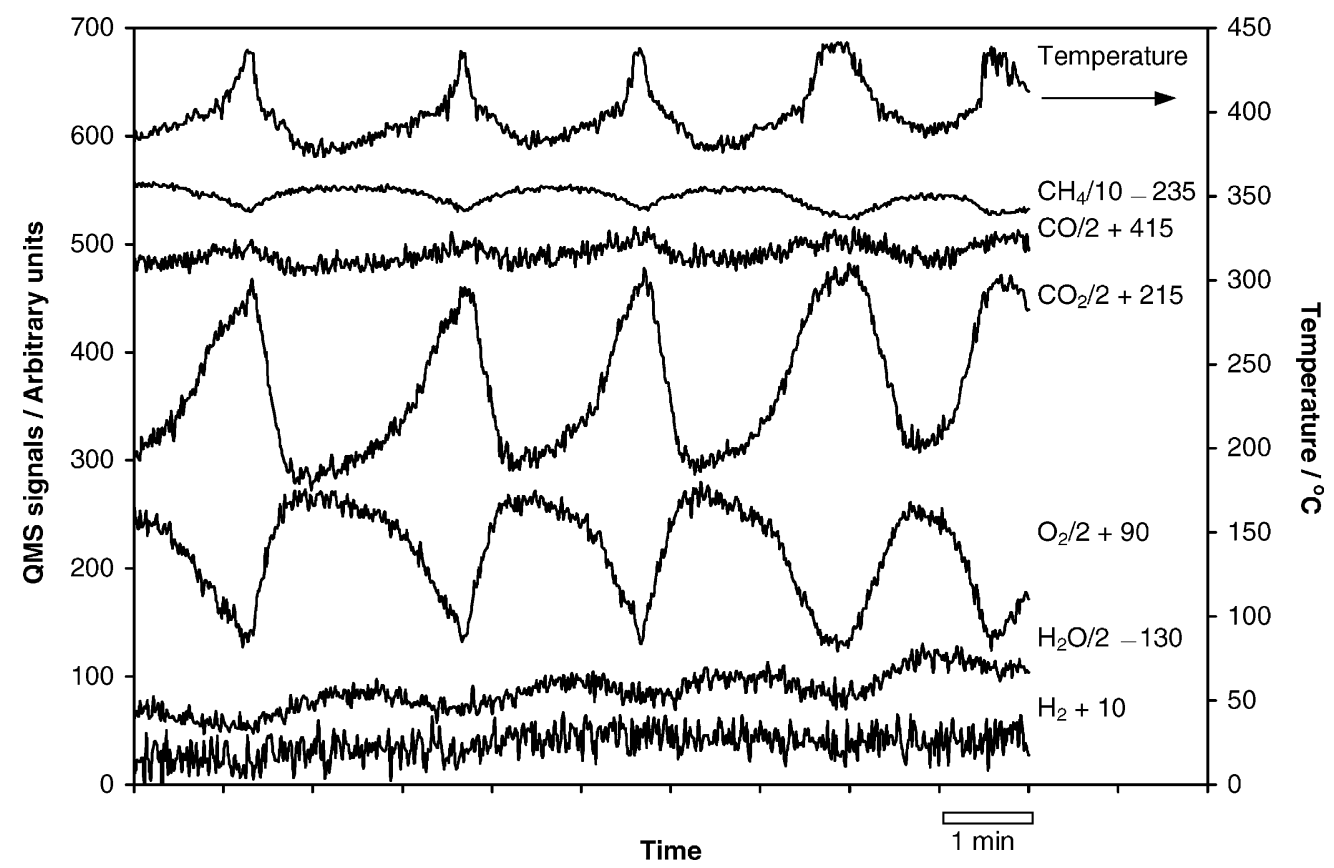

Fig. 4. Oscillations of methane oxidation over palladium wire in the temperature range of $379-440{ }^{\circ} \mathrm{C}$, with methane/oxygen ratio $9: 1$.

the legends. Oscillations were observed at temperatures in the range of $345-580^{\circ} \mathrm{C}$ and for gas mixtures with methane/oxygen ratios from $2: 1$ to $29: 1$. When only the chromel and alumel wires of the thermocouple were present, the reaction temperature had to be raised to about $800{ }^{\circ} \mathrm{C}$ before any oscillations could be observed. Thus, the results reported here must refer to reactions on the palladium. In general, maxima in the product oscillations of $\mathrm{CO}_{2}$ and $\mathrm{CO}$ corresponded to minima in the $\mathrm{CH}_{4}$ and $\mathrm{O}_{2}$ reactant oscillations. No hydrogen was observed to be generated during methane oxidation when a palladium catalyst was used. It is noticeable in all the figures that the water signal does not follow the $\mathrm{CO}_{2}$ signal particularly well even though both are products of the reaction. The mass spectrometer response to water appeared to be rather sluggish. This could have been caused by condensation somewhere in the system, but the existence of heating tapes was meant to prevent this. An alternative explanation will be discussed in detail in a later section.

The frequency and amplitude of the oscillations observed both in the reaction temperature, product and reactant concentrations were found to vary with the average temperature and the methane/oxygen gas ratio. It was also observed that features of the waveforms were not always stable and reproducible at any given temperature or feed gas methane/oxygen ratio. The responses shown in Figs. 5 and 6 were the typical waveforms observed for both the palladium foil and wire at low methane/oxygen gas ratios for a set temperature, while those in Figs. 7 and 8 were the corresponding waveforms of high methane/oxygen gas ratios. Various oscillatory waveforms were observed such as relatively simple sharp peaks, broad double or multiple peaks and also broad plateau peaks.

Two contrasting types of oscillations were observed. In the first, typified by Fig. 1, the catalyst was in an inactive state for most of the time with occasional bursts of $\mathrm{CO}_{2}$ and some $\mathrm{CO}$. There was always a relatively slow build-up to the bursts followed by a much more rapid cessation of activity. The second type of behaviour was almost the inverse of the first and typified by Figs. 6 and 8. Here, the catalyst was in the active state for most of the time with regular sharp reduction in activity. In this case, the drop in activity was always much sharper than the subsequent rise. All oscillations ceased, in both the palladium foil and 


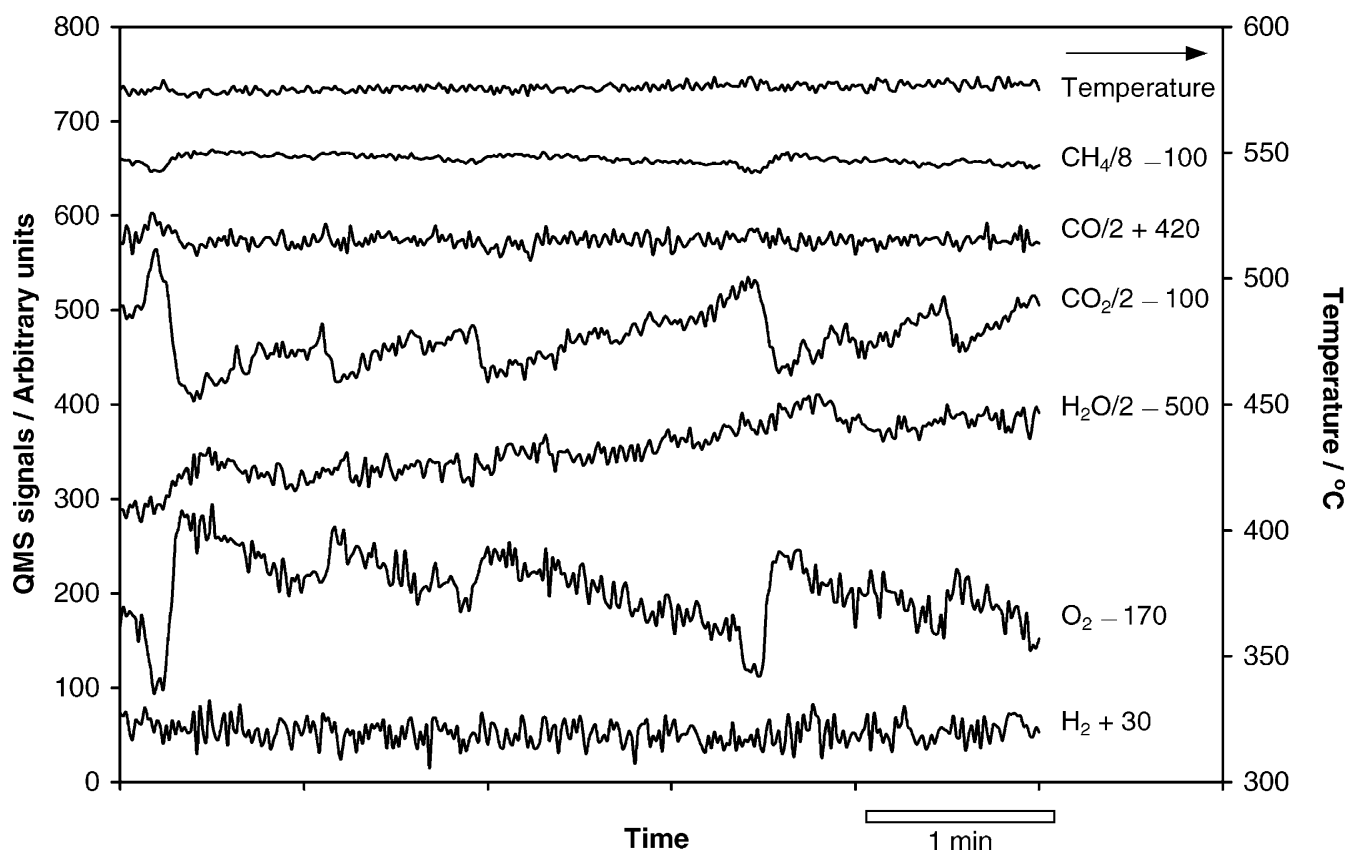

Fig. 5. Oscillations of methane oxidation over palladium foil in the temperature range of $572-580^{\circ} \mathrm{C}$, with methane/oxygen ratio $2: 1$.

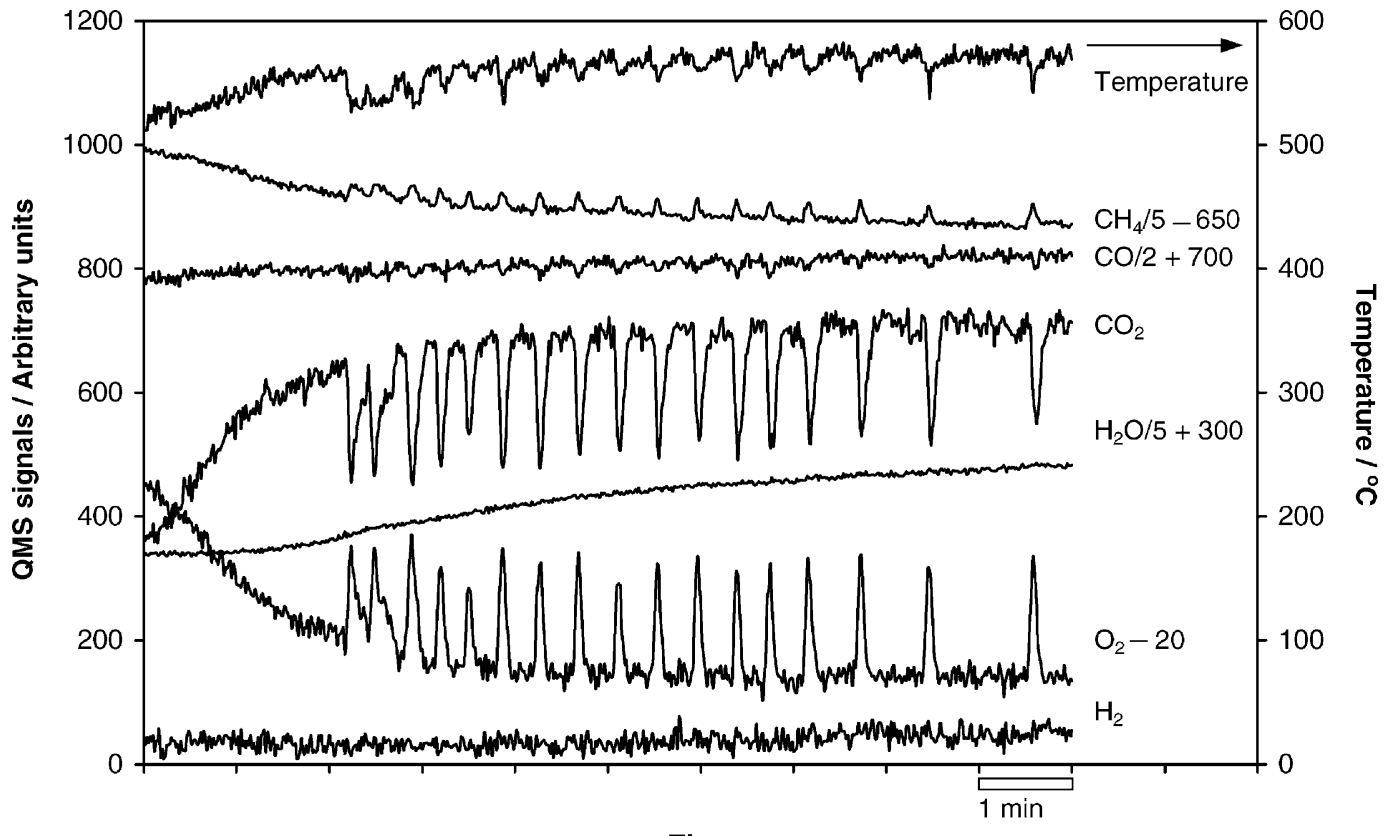

Fig. 6. Oscillations of methane oxidation over palladium wire in the temperature range of $564-576^{\circ} \mathrm{C}$, with methane/oxygen ratio $5: 1$. 


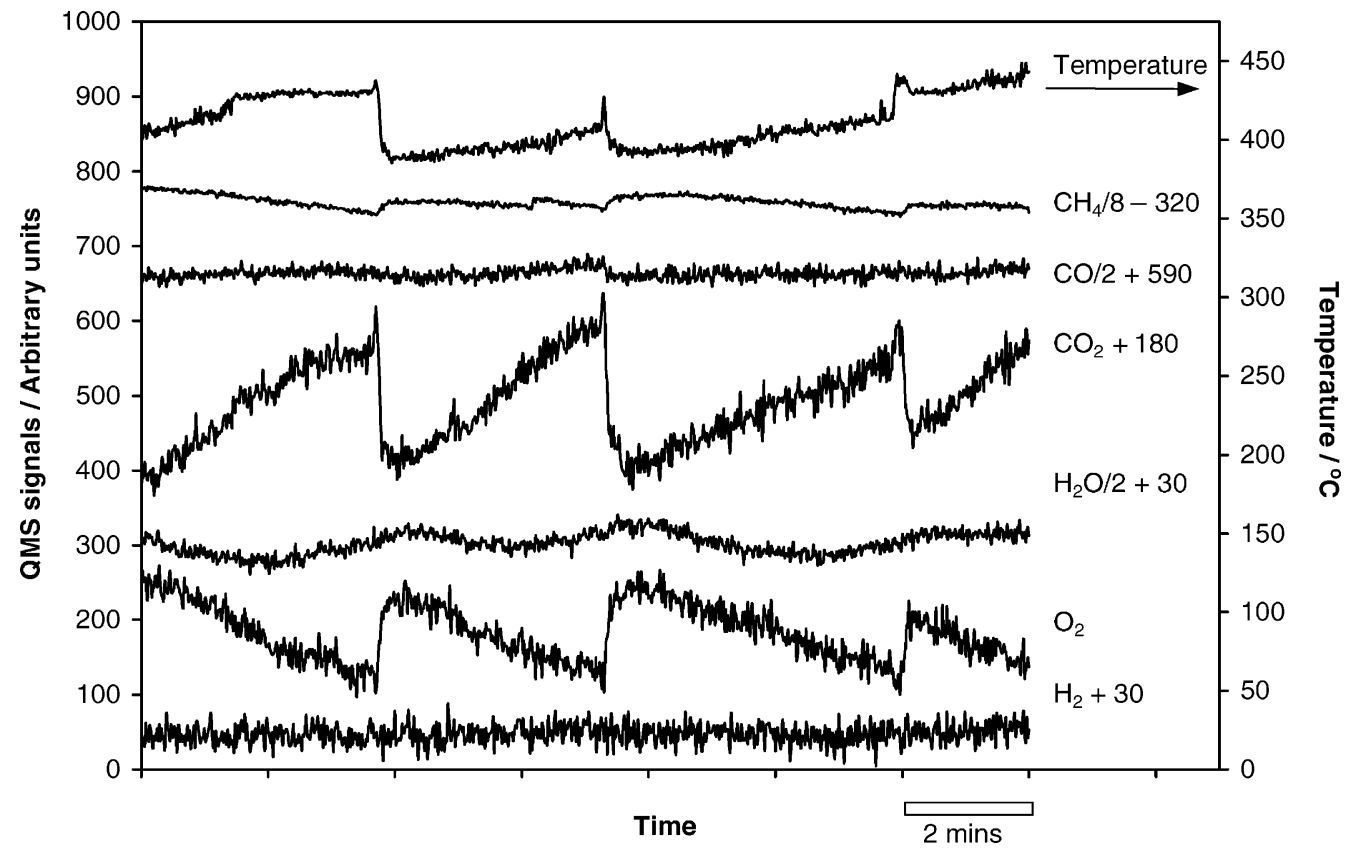

Fig. 7. Oscillations of methane oxidation over palladium foil in the temperature range of $386-442{ }^{\circ} \mathrm{C}$, with methane/oxygen ratio $14: 1$.

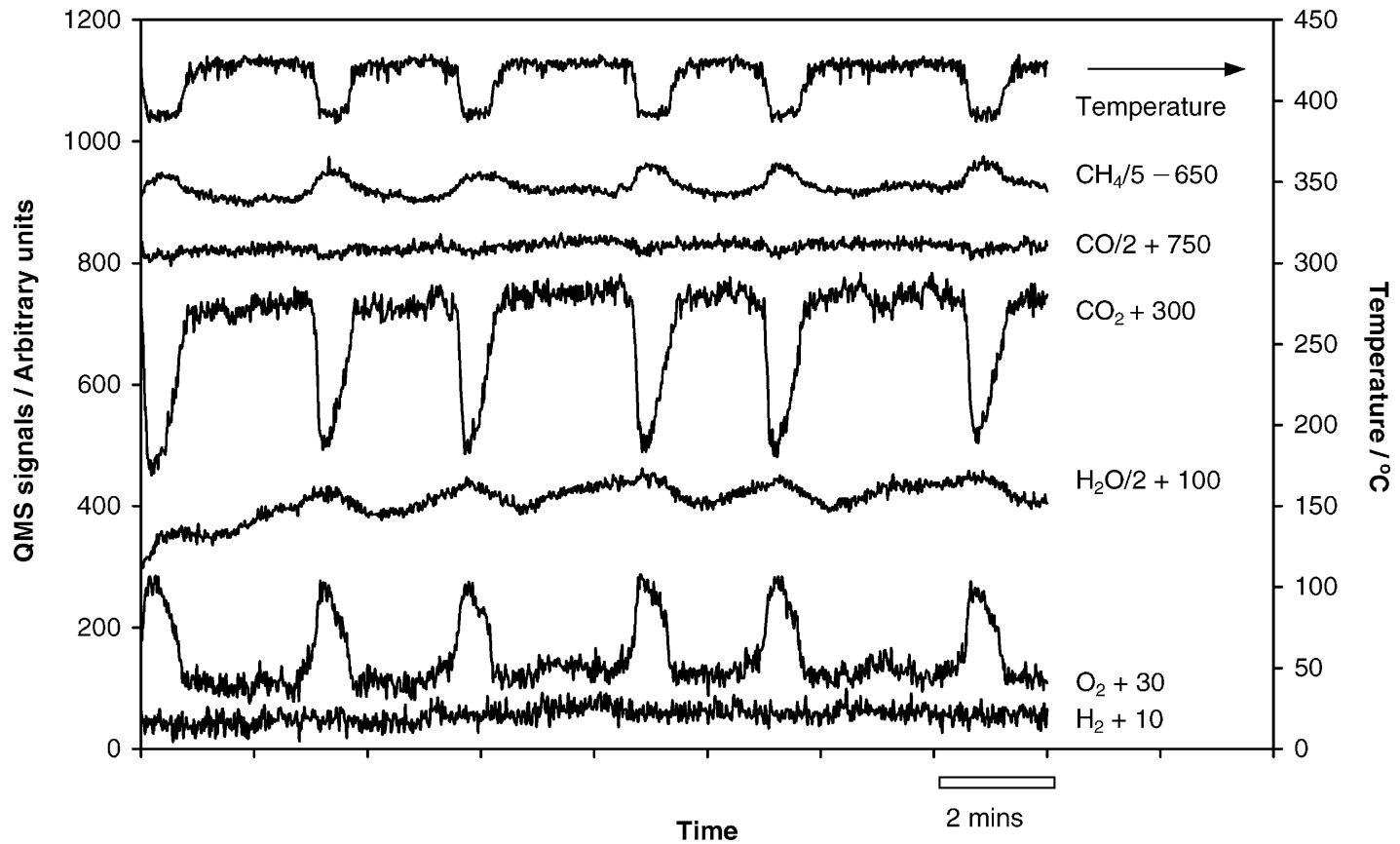

Fig. 8. Oscillations of methane oxidation over palladium wire in the temperature range of $389-425^{\circ} \mathrm{C}$, with methane/oxygen ratio $14: 1$. 
Table 1

QMS analysis data in the temperature range of $370-450{ }^{\circ} \mathrm{C}$ for palladium foil

\begin{tabular}{rlllll}
\hline $\mathrm{CH}_{4} / \mathrm{O}_{2}$ ratio & \multicolumn{2}{l}{ Change in QMS signal during oscillations } & Average period of oscillation (s) \\
\cline { 2 - 5 } & $\mathrm{CO}_{2}$ & $\mathrm{CO}$ & $\mathrm{O}_{2}$ & $\mathrm{CH}_{4}$ & \\
\hline $5: 1$ & +550 & +80 & -440 & -310 & 610 \\
$9: 1$ & +320 & +50 & -240 & -180 & 107 \\
$14: 1$ & +190 & +40 & -120 & -120 & 245 \\
$29: 1$ & +120 & +20 & -110 & -110 & 600 \\
\hline
\end{tabular}

wire, when temperatures exceeded $600{ }^{\circ} \mathrm{C}$ and/or the methane/oxygen ratio was reduced to $1: 1$. Hysteresis in the activity during the oxidation of methane was also observed as the reaction temperature was cycled up and down. This behaviour, commonly seen with palladium during methane oxidation, has been studied by a number of researchers [14-16].

\subsection{Effects of varying feed gas methane/oxygen ratio}

\subsubsection{Effects on oscillatory behaviour over palladium foil}

The frequency, amplitude and waveform of the oscillations were strongly dependent on the methane/ oxygen gas ratio. Data for four different methane/oxygen ratios are shown in Table 1. It can be seen that the amplitude of the $\mathrm{CO}_{2}$ and $\mathrm{CO}$ oscillations increases with amount of oxygen present. The period between oscillations also decreases with oxygen content apart from the unusually large period observed at a methane/oxygen ratio of 5:1. This anomaly may be connected with a change in the nature of the waveform for the methane/oxygen ratios of 29:1, 14:1 and $9: 1$. The waveforms have a saw-tooth sharp whereas for a ratio of 5:1, the waveform consists of a spike, which can be seen in Fig. 1.

In general, the temperature was found to follow the oscillations of reactants and products, with increases in temperature coinciding with increases in $\mathrm{CO}_{2}$ production. This is to be expected because the production of $\mathrm{CO}_{2}$ is a highly exothermic process. However, the size of the temperature rise was not always proportional to the rise in the $\mathrm{CO}_{2}$ signal and there were occasions when the temperature would drop as the $\mathrm{CO}_{2}$ signal rose. This behaviour may be connected with the way in which the thermocouple was arranged, with the two junctions at opposite ends of the palladium foil. Thus, a rise in temperature near one terminal, but not the other, could be recorded either as a temperature rise or a fall, depending on which terminal was most affected.

\subsubsection{Effects on oscillatory behaviour over palladium wire}

When palladium wire was used as a catalyst, the frequency of the oscillations was found to decrease as the methane/oxygen gas ratio was increased from 5:1 to 14:1, as shown in Figs. 6 and 8. As the gas ratio was raised further to $29: 1$, oscillatory behaviour ceased. No oscillations were obtained when the gas ratio was reduced to 1:1. The maximum amplitude of oscillation was seen at a gas ratio of 9:1 and strong oscillations also occurred for gas ratios in the range of 5:1-14:1. The oscillations seen over both palladium wire and foil were not stable and were sensitive to very minor changes in the reaction conditions. It was also observed that the Pd wire was in the active state for most of the time with periodic cessation of activity, whereas the Pd foil was usually inactive with periodic bursts of activity.

\subsection{Behaviour of the water signal}

It was observed that the change in the $\mathrm{H}_{2} \mathrm{O}$ signal did not follow the changes observed with the $\mathrm{CO}_{2}$ and $\mathrm{CO}$ signals. There was no sudden fall or rise in the signal when the $\mathrm{CO}_{2}$ and $\mathrm{CO}$ signals peaked, merely a sudden change in the slope. This behaviour can be seen in all the figures.

Although this effect was first thought to be due to the condensation of water vapour occurring somewhere in the system, this reason appeared to be ruled out as the mass 18 signal was observed to follow the $\mathrm{CO}_{2}$ and $\mathrm{CO}$ signals fairly well in other experiment runs using nickel and cobalt catalysts respectively. This behaviour exhibited by the $\mathrm{H}_{2} \mathrm{O}(\mathrm{g})$ signals can be explained if the hydrogen generated during the oxidation of methane 
is stored in or on the palladium catalyst and only released slowly as water vapour. This process could be represented as:

$\mathrm{CH}_{4}(\mathrm{~g})+\mathrm{O}_{2}(\mathrm{~g}) \rightarrow \mathrm{CO}_{2}(\mathrm{~g})+4 \mathrm{H}($ stored $)$

and

$4 \mathrm{H}$ (stored) $+2 \mathrm{O}($ ads $) \rightarrow 2 \mathrm{H}_{2} \mathrm{O}(\mathrm{g})$

where $\mathrm{H}$ (stored) is stored either as $\mathrm{H}$ or $\mathrm{OH}$ on or in the palladium sample. During stage "a" (see Fig. 9), the amount of hydrogen in or on the palladium is increasing because the rate at which it is being formed is greater than the rate at which it is being lost as water vapour. Thus, the amount of water vapour will also be increasing, as it is proportional to the amount of hydrogen in the sample. When the rate of $\mathrm{CO}_{2}$ production suddenly drops, the amount of hydrogen stored in the sample will also begin to drop causing the rate of water production also to drop (stage "b"). Once the original level of $\mathrm{CO}_{2}$ production is restored, the cycle will start all over again as seen in stage "c", in Fig. 9.

According to the previous study, there are two ways in which the hydrogen could be stored. One of them is that the hydrogen could exist as interstitial hydrogen within the interstices of the palladium metal, as a precursor to the formation of palladium hydride. Results obtained by Lewis [17] on "the palladium hydrogen system" showed that the solubility of hydrogen in palladium at $500{ }^{\circ} \mathrm{C}$ and $1 \mathrm{~atm}$ hydrogen pressure corresponded to about $\mathrm{PdH}_{0.01}$. However, the measured hydrogen pressure was negligible throughout the experiments carried out here with palladium, so that the concentration of dissolved hydrogen was likely to be very small. Nevertheless, a large concentration of hydrogen adatoms on the surface might be sufficient

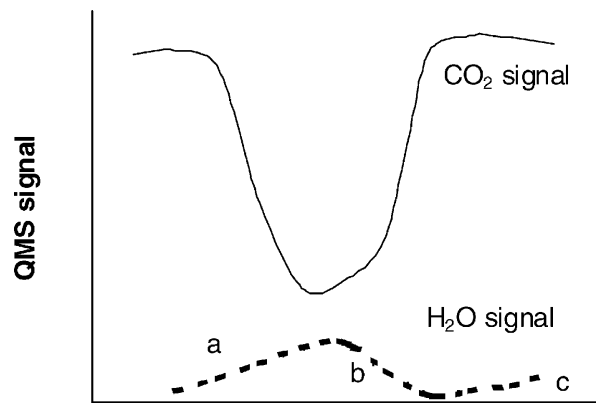

Fig. 9. Behaviour of water vapour signal. to induce significant hydrogen solution and this could well exist during the decomposition of methane. An alternative way of storing hydrogen could be as hydroxyl groups adsorbed on the surface. Such an intermediate has been proposed by Fujimoto et al. [18], where the following reaction steps were postulated:

$\mathrm{CH}_{4}(\mathrm{~g})+\mathrm{O}$ (ads) $\rightarrow \mathrm{CH}_{3}($ ads $)+\mathrm{OH}($ ads $)$

and

$2 \mathrm{OH}($ ads $) \rightarrow \mathrm{H}_{2} \mathrm{O}(\mathrm{g})+\mathrm{O}($ ads $)$

It was believed that reaction (4) must be reversible because water vapour acted as an inhibitor for the reaction. Such an intermediate would presumably be restricted to the surface and this raises the question as to whether sufficient hydrogen could be stored in this way to explain the buffer effect. However, the SEM photograph shows that the surface is highly porous and the surface area is therefore likely to be very large.

\subsection{Effects of varying temperature}

The furnace temperature has been varied in a range of $300-650{ }^{\circ} \mathrm{C}$ to examine the effect of temperature on the oscillatory behaviour over the palladium metal catalyst. It has been found that, in general, the frequency of the oscillations increased with temperature although, over a long period, this trend could be obscured by changes in the state of the surface. On palladium foil, in particular, hysteresis in the reactivity was observed when the reaction temperature was raised and lowered, confirming that complex changes were occurring on the surface.

\subsubsection{Temperature effects on oscillatory behaviour over palladium foil}

Oscillations were observed only at temperatures between 350 and $580^{\circ} \mathrm{C}$ where a methane/oxygen gas ratio of 5:1 was used. Below $350{ }^{\circ} \mathrm{C}$, methane oxidation proceeded slowly (low response) and without oscillations. Figs. 1 and 2 compare the behaviour of the oscillations at low and high temperatures. Although the oscillations obtained were sometimes irregular and not entirely reproducible, even under exact same reaction conditions, it was possible over a short period of time to observe a marked increase in the frequency of the oscillations as the temperature was raised, and to use this data to estimate the activation energies. 
It was found that there were two types of frequency dependence on temperature for the oscillations observed in different temperature ranges. At high average temperatures $\left(390-580{ }^{\circ} \mathrm{C}\right)$ the surface was in the high reaction mode for most of the time with periodic, but sudden, drops in activity. The temperature was fairly constant for most of the cycle and fairly well defined. It was found the a plot of $\ln (t)$, where $t$ is the oscillation period, against the reciprocal of the absolute temperature gave a good straight line, as shown in Fig. 10. We will assume that there is some reaction controlling the frequency of the oscillations with rate constant, $k$. The dependence of $k$ on temperature is given by the Arrhenius equation:

$k=A \exp \left(-\frac{E_{\mathrm{a}}}{R T}\right)$

where $A$ is the pre-exponential factor and $E_{\mathrm{a}}$ is the activation energy of the reaction. Since $t$ is proportional to $1 / k$, the equation can be written as:

$t=A^{\prime} \exp \left(-\frac{E_{\mathrm{a}}}{R T}\right)$

where $A^{\prime}$ is also a constant. The activation energy for the process was calculated to be $68 \pm 6 \mathrm{~kJ} \mathrm{~mol}^{-1}$.
At low average temperatures $\left(340-390{ }^{\circ} \mathrm{C}\right)$, the surface was found to be in a low reactivity mode for most of the cycle with periodic bursts of high activity. Again, the temperature was fairly constant for most of the cycle and another Arrhenius plot was constructed for this data, as shown in Fig. 10. The activation here was found to be equal to $194 \pm 5 \mathrm{~kJ} \mathrm{~mol}^{-1}$, which is much greater than that calculated at high temperature.

\subsubsection{Temperature effects on oscillatory behaviour over palladium wire}

In general, similar oscillatory behaviour to that obtained over palladium foil was observed. Slow oxidation of methane was observed to proceed at $300^{\circ} \mathrm{C}$ and oscillations only started when the temperature exceeded $350{ }^{\circ} \mathrm{C}$. Although not clearly observed at all times, the general trend here was for the frequency and amplitude of the temperature, reactant and product oscillations to increase as the temperature was raised, see Figs. 3 and 4. The $\mathrm{CO}_{2}, \mathrm{CO}$ and $\mathrm{H}_{2} \mathrm{O}$ product signals were also observed to increase when the temperature was increased. At still higher temperatures, the oscillations slowly decreased and finally stopped when the temperature reached $600^{\circ} \mathrm{C}$.

When the logarithm of the time between each oscillation was plotted against the reciprocal of the reaction

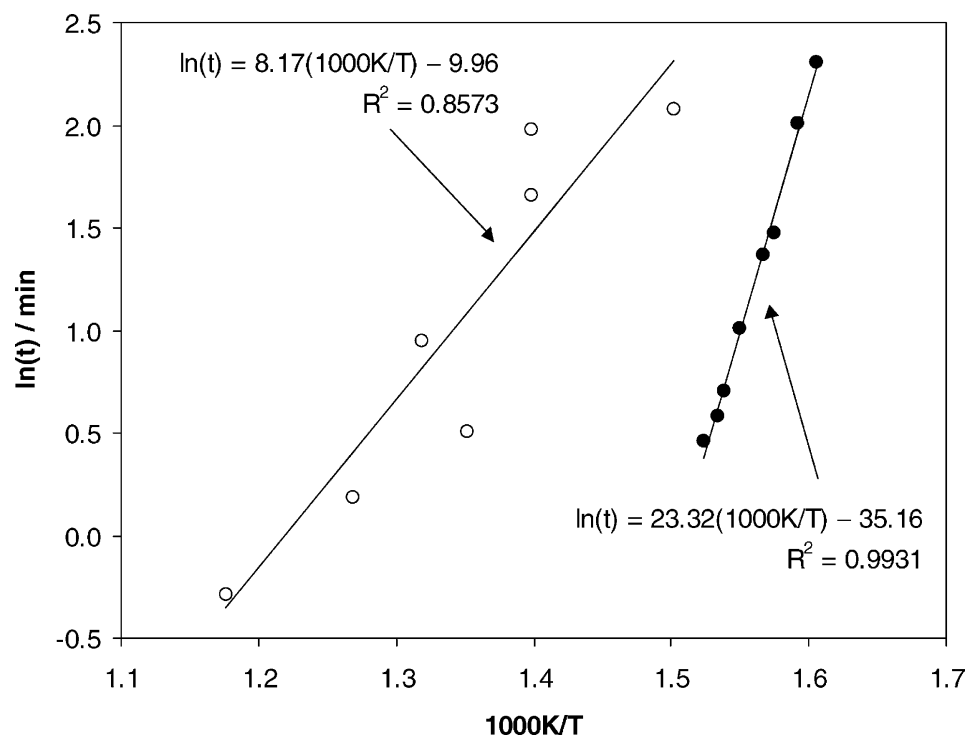

Fig. 10. Plot of $\ln (t)$ vs. $1000 K / T$ for palladium foil at $(\bigcirc)$ high temperatures, $E_{\mathrm{a}}=68 \pm 6 \mathrm{~kJ} \mathrm{~mol}^{-1}$ and $(\mathbf{O})$ low temperatures, $E_{\mathrm{a}}=194 \pm 5 \mathrm{~kJ} \mathrm{~mol}^{-1}$. 


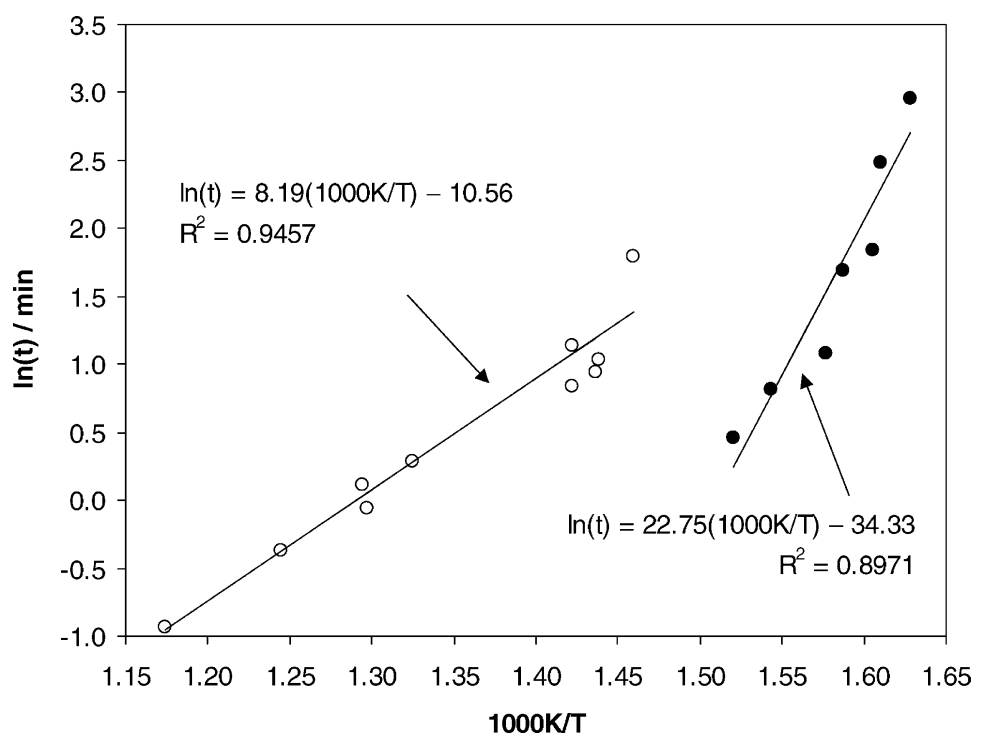

Fig. 11. Plot of $\ln (t)$ vs. $1000 \mathrm{~K} / T$ for palladium wire at $(\bigcirc)$ high temperatures, $E_{\mathrm{a}}=68 \pm 6 \mathrm{~kJ}^{\mathrm{mol}}{ }^{-1}$ and $(\mathbf{O})$ low temperatures, $E_{\mathrm{a}}=189 \pm 5 \mathrm{~kJ} \mathrm{~mol}^{-1}$.

temperature, plots with a good linear fit were obtained and observed to follow the Arrhenius equation, just as with the palladium foil (Fig. 11). For the higher temperature range, an activation energy of $68 \pm 6 \mathrm{~kJ} \mathrm{~mol}^{-1}$ was obtained and for the lower temperature range, an activation energy of $189 \pm 5 \mathrm{~kJ} \mathrm{~mol}^{-1}$ was obtained for oxidation of methane over palladium wires.

\subsection{Effects of cutting off methane or oxygen supply temporarily}

With both the palladium foil and wire, the oscillations ceased immediately when the methane gas supply was cut off to temporarily stop the reaction. This was accompanied by a drop in the temperature caused by a cessation of the exothermic reaction occurring on the surface. When the methane supply was restored to restart the reaction, the oscillatory behaviour of the oxidation reaction resumed and the temperature was also observed to return to its original level. This observation was seen for all the experimental runs studied using different methane/oxygen gas mixtures.

When the oxygen supply was turned off to temporarily stop the reaction, the oscillations were also observed to stop immediately for both the palladium foil and wire. This again was accompanied by a fall in the temperature but the drop in temperature was found to be somewhat less than that expected if there were no exothermic reaction occurring. Thus, heat was still being generated, presumably from the reaction of methane with palladium oxide. On restoration of the oxygen supply, an immediate surge in the reaction temperature was observed. This observation was also seen for all the experimental runs studied using different methane/oxygen gas mixtures. This is indicative that a very reactive form of carbon must have accumulated on the surface of the metal catalyst when the oxygen supply was cut off, and this reacted with $\mathrm{O}_{2}$ to form $\mathrm{CO}_{2}$ as soon as the $\mathrm{O}_{2}$ supply was restored. Under normal reaction conditions in the presence of oxygen, it is very likely that the carbon deposited from the decomposition of methane is oxidised immediately to carbon dioxide.

\subsection{Mechanism of the oxidation of methane over palladium catalysts}

\subsubsection{Thermodynamics of methane oxidation}

According to the results obtained for the oxidation of methane over palladium foil/wire catalyst, the 
primary reaction occurring can be written as:

$\mathrm{CH}_{4}(\mathrm{~g})+2 \mathrm{O}_{2}(\mathrm{~g}) \rightarrow \mathrm{CO}_{2}(\mathrm{~g})+2 \mathrm{H}_{2} \mathrm{O}(\mathrm{g})$,

$\Delta H_{298 \mathrm{~K}}=-802.7 \mathrm{~kJ} \mathrm{~mol}^{-1}$

Some CO was also produced during the reaction, therefore the reaction

$$
\begin{aligned}
& \mathrm{CH}_{4}(\mathrm{~g})+\frac{3}{2} \mathrm{O}_{2}(\mathrm{~g}) \rightarrow \mathrm{CO}(\mathrm{g})+2 \mathrm{H}_{2} \mathrm{O}(\mathrm{g}), \\
& \Delta H_{298 \mathrm{~K}}=-328.7 \mathrm{~kJ} \mathrm{~mol}^{-1}
\end{aligned}
$$

might also be occurring. However, there was evidence of the hydrogen going through a buffer state as discussed previously.

It was found from the experimental results that the QMS signals of both $\mathrm{CO}$ and $\mathrm{H}_{2}$ hardly changed at a very low level during the oscillation except some tiny peaks of $\mathrm{CO}$ observed which were in phase with the $\mathrm{CO}_{2}$ peaks. This indicated that both the reaction of the catalytic partial oxidation of $\mathrm{CH}_{4}$ and the water gas shift reaction were insignificant.

\subsubsection{Relative reactivity of the metal and oxide}

It is know that the oxidation of methane to $\mathrm{CO}_{2}$ and $\mathrm{H}_{2} \mathrm{O}$ occurs over both palladium oxide and the reduced metal surface. However, there is some disagreement in the literature over the surface form which is most active. Oh and co-workers $[19,20]$ and Hicks et al. $[15,16]$ argue that the metal surface is more active than the oxide surface, whereas Burch and co-workers [21-23], Farrauto et al. [24,25] and Primet and co-workers [26-28] consider the oxide surface as the most active phase.

The activation energies for the reaction over a palladium catalyst supported on $\alpha$-alumina, have been measured by Lyubovsky and Pfefferle [29], for both the oxidised and reduced surface states. They obtained a value of $73.2 \mathrm{~kJ} \mathrm{~mol}^{-1}$ for the oxide, in the temperature range $350-560^{\circ} \mathrm{C}$, and a much higher value of $157.2 \mathrm{~kJ} \mathrm{~mol}^{-1}$ for the metal at a higher temperature range of $690-830^{\circ} \mathrm{C}$. At higher temperatures, it was found that the metal-catalysed reaction was faster than the oxide-catalysed reaction, despite the much lower activation energy required for the latter process. This is explained if the pre-exponential factor in the rate equation is some $10^{5}-10^{6}$ times greater for the reaction over the metal than it is for the reaction over the oxide. This could only come about if the reaction over the oxide was restricted to a few defect sites, or to places where Pd and PdO occupy adjacent sites, as will be discussed later. Therefore, from the results observed by Lyubovsky and Pfefferle, the oxide surface seemed to be a better catalyst at low temperatures, with the size of the activation energy as the controlling factor, whereas the metal surface showed a faster reaction rate at higher temperature, when the pre-exponential term becomes dominant.

It was found that our lower activation energy $\left(68 \mathrm{~kJ} \mathrm{~mol}^{-1}\right)$, over both palladium foil and wire, was fairly close to the value $\left(73.2 \mathrm{~kJ} \mathrm{ml}^{-1}\right)$ quoted by Lyubovsky for the reaction of methane over the oxidised surface in the same temperature range. The higher activation energies obtained in our study $\left(189 \mathrm{~kJ} \mathrm{~mol}^{-1}\right.$ over palladium wire and $193 \mathrm{~kJ} \mathrm{~mol}^{-1}$ over palladium foil), however, do not correspond very well with the activation energy quoted for methane oxidation over the reduced surface and may well refer to a different process. In support of this observation, the temperature range over which the activation energy was measured in our work $\left(340-385^{\circ} \mathrm{C}\right)$ was much lower than the temperatures at which Lyubovsky studied the reaction over the reduced surface.

\subsubsection{Mechanism over palladium oxide and metal catalysts}

Fujimoto et al. [18] has provided a reaction rate expression for the methane oxidation reaction to form $\mathrm{CO}_{2}$ and $\mathrm{H}_{2} \mathrm{O}$ over $\mathrm{PdO} / \mathrm{ZrO}_{2}$ catalysts.

rate $=k\left[\mathrm{CH}_{4}\right]^{1.0}\left[\mathrm{O}_{2}\right]^{0.0}\left[\mathrm{H}_{2} \mathrm{O}\right]^{-1.0}$

It can be seen that the reaction rate is independent of the oxygen pressure and the water vapour acts as a poison to the reaction. It was also proposed that the rate determining step was the dissociate adsorption of methane on a site pair consisting of adjacent Pd and $\mathrm{PdO}$ species where palladium atom sites were considered to occur wherever there were oxygen vacancies on the $\mathrm{PdO}_{x}$ surface. More recently, Muller et al. [30] modified this mechanism in light of their experiments with isotopic scrambling using ${ }^{18} \mathrm{O}$ labelled $\mathrm{PdO} / \mathrm{ZrO}_{2}$ catalysts. The modified mechanism showed a redox cycle of palladium being set up, in which the palladium was alternatively reduced and reoxidised. Similar conclusions have also been reached by $\mathrm{Au}$-Yeung et al. [31] by either inserting ${ }^{18} \mathrm{O}$ isotope into the $\mathrm{PdO} / \mathrm{ZrO}_{2}$ catalyst or using ${ }^{18} \mathrm{O}_{2}$ in the gas phase, where $\mathrm{CD}_{4}$ 
was also used in place of $\mathrm{CH}_{4}$. Their results showed that the rate determining step being the activation of the $\mathrm{C}-\mathrm{H}$ bond, and the activation energies for the oxidation of $\mathrm{CH}_{4}$ and $\mathrm{CD}_{4}$ were calculated to be 176 and $180 \mathrm{~kJ} \mathrm{~mol}^{-1}$, respectively. It should be noted, however, that these values obtained by Au-Yeung et al. lie in the range generally attributed to reaction over the metal, and not the oxide.

Another mechanism was put forward by Su et al. [32], where it was considered that the formation of palladium metal nuclei in the oxide could promote the oxidation reaction, with the most active catalyst being a partially reduced oxide. This was supported by the theoretical analysis conducted by Broclawik et al. [33], where a density functional method was used to calculate the interaction energy of a methane molecule with a Pd-Pd dimer.

Studies have also been conducted on the palladium metal catalysts. It was found that adsorbed oxygen could suppress methane's adsorption, although methane is known to adsorb dissociatively on both supported and unsupported palladium metal [34]. It was also shown that each oxygen adatom on $\mathrm{Pd}\left(\begin{array}{lll}1 & 1 & 0\end{array}\right)$ blocks two active sites for dissociative adsorption of methane [35]. It is, therefore, likely that methane and oxygen will compete for sites in situations where both gases are present.

It is noticed that no oscillations were observed in any of these studies mentioned here, probably due to the oxygen-rich gas mixtures used. This was also observed in our studies that oscillations did not occur when the methane/oxygen ratio was lower that 2:1.

\subsubsection{Cause of oscillations}

Graham et al. [9] proposed that the oxidationreduction cycle arises from the variations in the oxygen pressure during reaction. Therefore, as the rate of reaction over the oxide increased, the oxygen pressure was thought to fall below the decomposition pressure of the oxide, which then reverts to the metal. This causes a drop in the reaction rate, with a consequential increase in the oxygen pressure, and the metal is re-oxidised.

The simple explanation just given does not account for some of the aspects of the data obtained in our study, although the variation in the oxygen pressure may be an important factor in maintaining the oscillations. A good example of this can be seen in the oscillations depicted in Fig. 10, where, prior to each sudden loss of activity, there was a period of more than 1 min during which the oxygen pressure remained almost constant at a very low value. Thus, there was no sudden drop in the oxygen pressure that can be correlated with the reduction of the oxide to the metal.

Although this was so, the variation in oxygen pressure may still be an important factor in the oscillations. The rate of methane oxidation is high in the oxidised state and nearly all of the oxygen will be consumed, provided there is excess of methane. Further reaction of methane with lattice oxygen, following the mechanism proposed by Muller et al. [30], will inevitably lead to the reduction of palladium oxide. Once the surface has been reduced to palladium metal, the rate of methane oxidation falls and the pressure of oxygen increases. Sufficient oxygen is now available for the re-oxidation of the metal to begin and so the cycle is repeated.

The following tentative model, see Fig. 12, is proposed to explain the type of oscillation seen in Fig. 8 at temperatures between 390 and $440^{\circ} \mathrm{C}$. The cycle starts with a layer of $\mathrm{PdO}_{x}$ crystals covering the metal surface. Metal sites exposed at defect or crystal boundaries will exist, and it is assumed that high reactivity

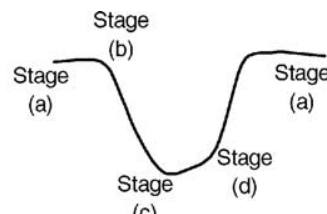

(c)

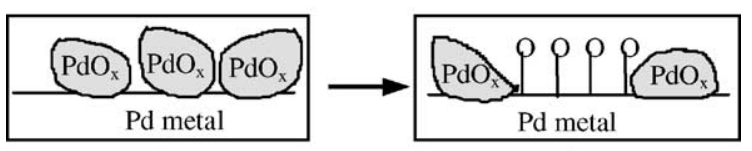

(b)

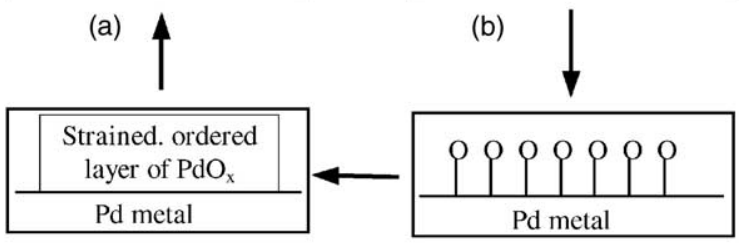

(d)

(c)

Fig. 12. Proposed reaction model. 
for the oxidation of methane will occur wherever there is an exposed metal atom adjacent to the oxide. At this stage, the rate of reaction will remain approximately constant because it is limited by the amount of oxygen available. Although some lattice oxygen is also consumed during the oxidation of methane, in addition to the constant supply of gas phase oxygen, this amount is assumed to be small compared to the overall rate of reaction and will therefore have a negligible effect on the overall rate of reaction.

Once all the oxide has been reduced, the rate of oxidation will fall rapidly to a value typical of the metal surface covered with an adsorbed layer of oxygen, the situation being depicted in Fig. 12(c), the oxygen pressure will then start to rise and the metal surface begins to re-oxidise. A thin, ordered oxide layer which has good cohesion with the underlying metal is assumed to form initially, as shown in Fig. 12(d). This layer is unlikely to provide many sites, where a metal atom and oxide anions are adjacent and so the rate of methane oxidation will also be small, but large than on the metal surface. When the oxide layer reaches a critical thickness, it is expected to rearrange to form regular oxide crystals which have reduced adhesion to the metal, providing more adjacent metal-oxide sites. At this stage, the rate of methane oxidation rises sharply and the whole process begins to repeat itself, beginning a new cycle.

This proposed model of oxide growth can be supported from the work carried out by Voogt et al. [36], who studied the adsorption of oxygen on a $\operatorname{Pd}\left(\begin{array}{lll}1 & 1 & 1\end{array}\right)$ surface and also on Pd foil, using ellipsometry, LEED, AES and XPS techniques. At high temperatures $\left(T>197^{\circ} \mathrm{C}\right)$ and oxygen pressures $\left(P>10^{-4} \mathrm{~Pa}\right)$, a surface oxide was identified, which have a complex LEED pattern on the Pd(III) surface. This showed that an ordered over layer had been formed, but the pattern could not be matched with any unreconstructed plane of bulk PdO. Bulk oxide was not observed in this work; however, Su et al. [32] have been able to study the later stages of oxidation using the relative intensity of a Raman band at $651 \mathrm{~cm}^{-1}$ to follow the growth of palladium oxide. Two types of oxide have been identified; an apparently amorphous form with a low Raman scattering cross section (possibly similar to the ordered oxide layer observed by Voogt et al. [36]) and a crystalline form with a higher cross section. Their results showed that the initial, so called amorphous, oxide layer slowly underwent crystallisation as the layer got thicker.

Good experimental evidence obtained in our work present also showed that hysteresis in the cycle of alternate formation and reduction of oxide layer was essential to maintain oscillations. Similarly, Farrauto et al. [25] found that palladium oxide supported on alumina decomposes in two distinct steps when heated in air at one atmospheric pressure. The first step was found to occur between 750 and $800{ }^{\circ} \mathrm{C}$, and believed to be the decomposition of a palladium-oxygen species dispersed on bulk palladium metal, designated $\mathrm{PdO}_{x} / \mathrm{Pd}$. The second step occurred between 800 and $850^{\circ} \mathrm{C}$ and was attributed to the decomposition of crystalline palladium oxide, designated PdO. Significant hysteresis was found between the decomposition of the oxide to palladium metal and reformation of the oxide, which did not occur until the temperature had dropped well below $650^{\circ} \mathrm{C}$.

\section{Conclusions}

Oscillatory behaviour exhibited during the oxidation of methane over palladium metal catalysts has been studied under various reaction temperatures and methane/oxygen gas ratios. Characterisation of the catalyst has also been carried out using SEM and XRD techniques. Results of the SEM surface analysis revealed the presence of a porous surface, clearly indicating that the metal surface had undergone a change since the reaction commenced. The diffraction pattern showed the palladium phase to be the dominant phase present. Hysteresis was observed in the activity of the reaction as the temperature was cycled up and down, showing that the metal surface was continually changing throughout the reaction.

The activation energies of the reaction during the high reactivity mode, (assumed to be $\mathrm{PdO}$ ), and low reactivity mode (assumed to be Pd) were also calculated. Oscillation rates were observed to depend on the dominant surface. Oscillations were frequent when the high reactivity mode was dominant. The activation energy of this mode was found to be low. When the low reactivity mode was dominant, the oscillations were slower and the activation energy was three times greater. Therefore, these results imply that the behaviour of the palladium surface, switching 
back and forth from the reduced state to the oxidised state, is responsible for the oscillatory behaviour seen in this system. A simplified model explaining the oscillations has been proposed.

\section{References}

[1] D. Konig, W.H. Weber, B.D. Poindexter, J.R. McBride, G.W. Graham, K. Otto, Catal. Lett. 29 (1994) 329.

[2] Y.Q. Deng, T.G. Nevell, Faraday Discuss. 105 (1996) 33.

[3] U.S. Ozkan, M.W. Kumthekar, G. Karakas, J. Catal. 171 (1997) 67.

[4] Y.Q. Deng, T.G. Nevell, J. Mol. Catal. A 142 (1999) 51.

[5] Y.H. Hu, E. Ruckenstein, Ind. Eng. Chem. Res. 37 (1998) 2333.

[6] J.G. Cohn, Ind. Eng. Chem. Res. 38 (1998) 1740.

[7] Y.H. Hu, E. Ruckenstein, Ind. Eng. Chem. Res. 38 (1998) 1742.

[8] X.L. Zhang, D.O. Hayward, D.M.P. Mingos, Catal. Lett. 72 (2001) 147.

[9] G.W. Graham, D. Konig, B.D. Poindexter, J.T. Remillard, W.H. Weber, Top. Catal. 8 (1999) 35.

[10] U.S. Ozkan, M.W. Kumthekar, G. Karakas, J. Catal. 171 (1997) 67.

[11] L.F. Adams, Engineering Measurements, Instrumentation, The English Universities Press, London, 1975, p. 368.

[12] J.J. Chen, E. Ruckenstein, J. Phys. Chem. 85 (1981) 1606.

[13] E. Ruckenstein, J.J. Chen, J. Catal. 70 (1981) 233.

[14] P. Salomonsson, S. Johansson, B. Kasemo, Catal. Lett. 33 (1995) 1.

[15] R.F. Hicks, M.L. Young, R.G. Lee, H. Qi, J. Catal. 122 (1990) 279.

[16] R.F. Hicks, H. Qi, M.L. Young, R.G. Lee, J. Catal. 122 (1990) 295.
[17] F.A. Lewis, The Palladium Hydrogen System, Academic Press, New York, 1967.

[18] K. Fujimoto, F.H. Ribeiro, M. Avalos-Borja, E. Iglesia, J. Catal. 179 (1998) 431.

[19] S.H. Oh, P.J. Mitchell, R.M. Siewert, J. Catal. 132 (1991) 287.

[20] S.H. Oh, P.J. Mitchell, Appl. Catal. B: Environ. 5 (1994) 165.

[21] R. Burch, F.J. Urbano, Appl. Catal. A: Gen. 124 (1995) 121.

[22] T.R. Baldwin, R. Burch, Appl. Catal. 66 (1990) 337.

[23] T.R. Baldwin, R. Burch, Appl. Catal. 66 (1990) 359.

[24] R.J. Farrauto, M.C. Hobson, T. Kennelly, E.M. Waterman, Appl. Catal. A: Gen. 81 (1992) 227.

[25] R.J. Farrauto, J.K. Lampert, M.C. Hobson, E.M. Waterman, Appl. Catal. B: Environ. 6 (1995) 263.

[26] P. Briot, M. Primet, Appl. Catal. 68 (1991) 301.

[27] E. Garbowski, C. Feumi-Jantou, N. Mouaddib, M. Primet, Appl. Catal. A: Gen. 109 (1994) 277.

[28] N. Mouaddib, C. Feumi-Jantou, E. Garbowski, M. Primet, Appl. Catal. A: Gen. 87 (1992) 129.

[29] M. Lyubovsky, L. Pfefferle, Catal. Today 47 (1999) 29.

[30] C.A. Muller, M. Maciejewskii, R.A. Koeppel, Catal. Today 47 (1999) 245.

[31] J. Au-Yeung, K. Chen, A.T. Bell, E. Iglesia, J. Catal. 188 (1999) 132.

[32] S.C. Su, J.N. Cartens, A.T. Bell, J. Catal. 176 (1998) 125.

[33] E. Broclawik, R. Yamauchi, A. Endou, M. Kubo, A. Miyamoto, J. Mol. Catal. 119 (1997) 35.

[34] F. Solymosi, A. Erdohelyi, J. Cserenyi, A. Felvegi, J. Catal. 147 (1994) 272.

[35] M. Valden, J. Pere, N. Xiang, M. Pessa, Chem. Phys. Lett. 257 (1996) 289.

[36] E.H. Voogt, A.J.M. Mens, O.L.J. Gijzeman, J.W. Geus, Surf. Sci. 373 (1997) 210. 